\title{
A South African Distance Learning Case Study: Reducing Distance through Mobile Technology
}

\author{
Patrick Nkhangweleni Mafenya \\ Institute for Open and Distance Learning \\ University of South Africa, Pretoria, South Africa \\ Email: mafennp@unisa.ac.za
}

\section{Doi:10.5901/mjss.2014.v5n14p276}

\begin{abstract}
This study grew out of the critiques of the University of South Africa's (Unisa) failure to access all its students through the use of information communication technologies (ICTS), mobile technologies in particular. Previously, distance education universities communicated with their students mainly by post, which at times got lost or take too long to reach them. In view of the unreliability of the post method, this study seeks to explore the probabilities and cost effectiveness of using mobile technology to reduce the transactional distance that exists between student and instructor, student and peers, student and the institution. A qualitative approach was used to gather data from students and staff in order to capture their views on using mobile technologies to reduce the distance that exists between them. The research question: 'How can Unisa as an ODL institution tap into these kinds of mobile technologies to reach and increase student participation in ODL?' provided the focus for the study. Unstructured-interviews were conducted to capture their views. Data were collected, recorded and analysed using Coliazzi's methodological framework. This framework was chosen because of its ability to provide clarity in the steps of analysis and was followed by an analysis of the impact that mobile technology could have on reducing this psychological distance. The study revealed that if properly utilised, mobile technology has the potential to reduce the gap between the student and the instructor, student and peers, student and the institution.
\end{abstract}

Keywords: Mobile technology, mobile learning, open distance learning

\section{Introduction}

The purpose of this study was to explore and describe the possibilities of reducing or narrowing the gap that exists between the student and the educational instructor through the utilisation of mobile technology in a South African distance education context. In distance education, students are physically, emotionally and socially separated from the institution. In this separation there is a psychological and communication space that has to be crossed, a space of potential misunderstandings between instructors and students (Moore, 1991).

The justification for this exploration is based on the understanding that educational technologies have the potential of expanding educational opportunities for disadvantaged and the marginalized students. The idea is to use these devices that are already available and accessible to our students in order to develop ways in which we could support distance learners. Mobile technology makes such information readily accessible. The use of mobile technologies for education is much more potent in South Africa because it has the ability to connect-less privileged people to information. The lack of infrastructure for electricity, computers, and telephones in some parts of South Africa has led to the rapid growth of wireless infrastructure. The number of subscribers of cell phone use in South Africa has increased over a thousand times in the last few years.

More than ninety percent of Unisa's students own smart cell phones that have a lot of features. The current demand in communication technologies drives new inventions in digital technologies, some of which are mobile phones. For instance, the phoning industry has used this demand to develop advanced mobile phones (Nokia N95, iPhone, Blackberry), which have multiple functions for e-mail, instant messaging and internet, photographing and videos as tools to create, access and communicate information (McNeal \& Van't Hooft, 2006). The ubiquity of emerging mobile technology devices has resulted in debate and research on how it can benefit teaching and learning, as much as it benefits business, industry, and other social activities (Alexander, 2004). The incorporation of mobile technology, such as cell phones, in education can address this need because they can enable interaction between a student and the instructor, as well as between a student and her or his peers (Makoe, 2012).

The advantage of mobile learning is the two-way communication between communities and their educational 
institutions. The two way communication brings community resources into the classroom through learners and takes the classroom resources into the community through the teacher-facilitator (Keegan, 2006). Mobile learning, therefore, has the potential of reaching a wider audience than the classroom, especially where cellular infrastructure and network have been highly developed. Apart from students or learners in the traditional sense, mobile learning can cater for anyone, anytime, anywhere who is in need of information for the betterment of their lives. This study therefore, wants to find out if student support through mobile technologies can help the student to feel less isolated from the educator, the institution and other students. This is sufficient reason and motivation for distance education providers to explore the possibility of making a cell phone an important tool in the educational system.

\section{Literature Review}

Open and distance learning (ODL) is a system of education that uses modern communication facilities including high speed internet connection, computers, and broadcasting systems to facilitate learning process (Attewell, 2005). Even though there are several studies that have been conducted on using mobile technology worldwide, there are still limited studies on the exploration of using mobile technology, cell phone in this context not only as talking tool but as a learning tool. The most important question to be answered in this study is: "how can we harness mobile technology as a tool to reduce the distance between the student and the educational instructor in a distance education context?'

This paper reflects upon the use of this technology to demonstrate how the University of South Africa can use it to reach out some disadvantaged students or people in different parts of South Africa and the world. Reaching the disadvantaged students in South Africa has been identified by several studies as one of the reasons for exploring the use of mobile or wireless devices in learning. The cell phone has been argued to be an appropriate device for educational delivery in the so-called developing world, and currently it is the most widely used medium in South Africa and has major educational implications. According to Brown (2003) even though it is largely purchased for voice communication-which semi-literate users rely on for their social and economic needs-it is also able to run educational software that supports visuals and voiceovers. In a developing country like South Africa, particularly rural areas, many educational institutions are not only poorly equipped, but also have a lack of highly trained educators. Suplido., Bonito., Escubio and Mariano (2003) have discussed four types of cell-phone usage:

- The cell phone and SMS is used a course delivery tool, even to the point of being the primary medium for interactive learning of course content

- Short message system (SMS) is also used to give lecture alerts (changes of schedule), schedules of focus group discussions, examination reminders, deadlines for projects and papers, new courses, grades, schedules for consultation, availability of library resources, and so on.

- In extra-curricular contexts, student groups and organisations use cell phone to promote activities such as job fairs, social affairs, and discount opportunities, and for text-voting during student council elections.

- In administrative contexts, the following details are readily available over the phone: university admissions, fees, availability of scholarship grants, marketing campaigns, alerts to parents and guardians on the students' performance, and emergency information such as bad weather alerts and suspension of classes.

Most users, however, do not see the cell phone's potential for education, nor even for the communication functions for which it was originally designed (Librero, 2006). As of now, three out of every five people in South Africa has a cell phone and it is therefore proper to venture into the use of this technological gadget to provide distance education to the people since it is cheap and affordable to many people. As distance education remains a strategy for increased access in education because of its broad constituency (Garrison \& Shale, 1990), mobile learning enriches distance learning by making learning more flexible to reach people other learning approaches cannot reach, such as the disadvantaged homeless, immigrants, powerless women and people with disability, the rural poor and many others. Support services like tutorials, library, guidance and counselling, and academic and administrative consultations, must be available in a wide variety of forms, such as online and via SMS. This is very important because many South Africans do not have easy and ready-made access to the internet.

According to Venter (2003), cellular phones can facilitate cohort socialization between and among students or can serve as a support mechanism to encourage students along in their distance education. Socialization via cell phones can provide that much needed thwart feelings of isolation, and promote their sense of belonging, psycho-social aspects that were typically missing in older generation of distance education (Thorpe, 2002). New communication technologies, particularly the internet and cell phones appear to offer exciting possibilities for overcoming geographical access and cost barriers to learning (Stead, 2006). For instance, Short Message service (SMS) is highly cost-effective and a very reliable 
method of communication. It is less expensive to send an SMS than to mail a reminder through regular postal mail, or even follow-up via a telephone call. Besides SMS, distance learners can use mobile phones to listen to their course lecturers, and for storage and data transfer. There is a wide range of roles for mobile technologies supporting the learner in many ways ranging from relatively simple use of SMS texting to the more advanced use of smart-phones for content delivery, project work, searching for information and assessment (Khan, 2001).

Viljoen, Du Preez and Cook (2005) indicate that teaching and studying at a distance can be as effective as traditional instruction when the method and technologies used are appropriate to the instructional tasks with intensive learner-to-learner interactions and instructor-to-learner interactions. In their study they discovered that about 95\% of South Africa has mobile network coverage. The number of cell phone subscribers has exploded and as a result there are now more mobile subscribers than fixed landline telephone subscribers in South Africa. It is only less than $11 \%$ of South Africa's population that relies on landline telephone lines. Given the proliferation of mobile telephone use across all sectors of South African society, it is increasingly evident that this highly mobile form of technology and infrastructure can be leveraged to deliver flexible-educational opportunities to more and more South Africans. In other words, simple, lowcost cellular mobile telephones are now helping South Africans bridge the once formidable digital divide (Viljoen et al, 2005).

Even though various initiatives have been taken to make use of mobile technologies for education at Unisa, mobile phones can only handle so much information, particularly given the capacity of mobile phone models currently in use. One of the major challenges facing the University of South Africa, as an ODL institution, is to provide support mechanisms for those students who are geographically isolated from their teachers as sources of information and separated from their peers as sources of support (Makoe, 2012). Moore (2003) argues that distance education, is not only a geographic separation between the teachers and the learners, it is a pedagogical concept. The challenge of addressing the issue of separation and isolation is even more acute in places of limited resources such as rural South Africa. Research undertaken in South Africa indicates that $80 \%$ of students surveyed embrace the idea of learning through the use of mobile phones. According to Makoe (2012) the potential of using cell phones for educational purposes is enormous in a country of limited access to electricity and telephone networks, poor roads and postal services, and fewer people who have expertise of using computers.

However, one possible hurdle to educating people in becoming familiar with technology is the lack of trained educators within developing countries where there is little to no technological training currently available. One way to overcome this obstacle is to establish a blended learning programme that involves the inclusion of distance learning, as well as some face-to-face learning (Khan, 2001). Moreover, given the recent evidence that indicates the opportunities of using distance learning to transform the student learner, there is a reason to believe that using a blended learning approach, or one where a technological and a face-to-face learning component is included, can help in the development of better global, technological communities.

Apart from students or learners in the traditional sense, mobile learning can cater for anyone, anytime, anywhere who is in need of information for the betterment of their lives (Januszewski \& Yeaman, 2001). Using multi-media facilities like videos, audios, graphic and interesting textual descriptions, it is possible to reach the remote locations of the world where computer technology has not reached yet (Jung, 2001). The most serious issue faced by mobile learning is the lack of a solid theoretical framework which can guide effective instructional design and evaluate the quality of programs that rely solely on mobile technologies.

\section{Theoretical Framework}

According to Moore (1991, pp.1-6) "Research that is not grounded in theory is wasteful". Even though unisa was the first dedicated distance education institution in the world, it has lagged behind in using educational technologies to access its students who are scattered throughout the country and the diaspora. Against this back drop this study has made use of Moore's transactional distance theory. This theory was regarded as the most suitable one for this study because of its ability to respond to the research question and the research objectives. Most recently, Moore has described it as: "The transaction that we call distance education occurs between individuals who are teachers and learners, in an environment that has the special characteristic of separation of one from another, and a consequent set of special teaching and learning behaviors. It is the physical separation that leads to a psychological and communications gap, a space of potential misunderstanding between inputs of instructor and those of the learner, and this is the transactional distance." (Moore, 1991, pp. 1-6). 


\section{Methodology}

The research methodology for this study was grounded in a qualitative phenomenological framework to explore and describe Unisa's failure to utilise mobile technology to reduce the psychological distance that exists between students and the instructor, student and the institution. To understand students' views and experiences on the impact that could be made by the use of mobile technology, participants were selected from a single ODL South African university in order to minimise organisational variation. Within this university the researcher selected ten first year participants who in this case were students from various faculties. Out of the ten students interviewed, five were coming from disadvantaged and previously marginalised rural areas and the other five came from the urban centres. These students were expected to answer the research question: "how can we harness mobile technology as a tool to reduce the distance between the student and the educational instructor in a distance education context?'

The inclusion criteria for these students were based firstly, on the understanding that they should be registered for the current academic year, and secondly, they should be in their first year of study at Unisa. These students were used for this study because they were better positioned to provide the researcher with relevant purposeful information since they are directly affected by the way this kind of support reaches them. Phenomenology was adopted as a research approach because of its ability to provide clarity on the steps that should be followed when collecting and analysing data. To ensure that the study was conducted in accordance to the ethical principles, the researcher applied for an ethical clearance from the University of South Africa's Ethical Committee. Participants were promised confidentiality in order to improve the accuracy of the information supplied. Unstructured interviews were used as the primary unit to capture the views of the participants on bridging the gap between them and the institution through the use of mobile technology. Data were collected until saturation was reached. This was evidenced by the participants' failure to come up with new information. Data were audio-recorded and transcribed. Finally, data were analysed through the use of Colliazi's (1978) framework. The following stages were employed to analyse data:

- Step one: The researcher started by reading the entire interview to get a sense of the whole

- Step two: The whole transcription was disseminated into several parts to determine the meaning expressed

- Step three: Relevant themes were clustered together according to meanings

- Step four: Descriptions were given back to the participants for verification

- Step five: In order to understand students' experiences the researcher had to move from individual phenomenological structure to the general description of situated structures. It is through this process that several themes were identified from each participant and then clustered into a number of general themes that appeared to be common to all the participants' descriptions. The final step in data analysis involved an interpretation or meaning of data, and it was at this stage that the clustered themes and meanings were used to develop the textural descriptions of the experiences. From the textural and structural description an integration of the meanings and essences of the phenomenon were constructed. This included making use of the verbatim examples from the transcribed interviews.

To achieve study trustworthiness the researcher embarked on the process of triangulating the information obtained through unstructured interviews by making use of two researchers from his department to verify what the participants have said.

\section{Discussions}

The findings of this study were presented in terms of the participants' views, perceptions and experiences that they shared with the researcher at the time the interviews were conducted. On the basis of the data collected, recorded and analysed the findings of this study fall into the following themes: isolation, limited electrical infrastructure, inadequate human resources capacity, lack of financial resources and limited band-with. Most of the distance education students are geographically isolated throughout the country and it became clear that engaging them is a challenge. Since the dawn of this new mobile technologies distance education students are becoming more and more able to communicate with each other with the result that the transactional distance that exists between the student and the instructor, the student and the institution, student and student is drastically reduced (Venter, 2003). This assertion is supported by what one of the instructors interviewed had to say: 'There is actually a shift in the mind set: most of my students are now used to the fact that ICT bridges the distance between me and them. I am currently having students in the tele-education programme who are geographically distributed. Those within can attend live delivery sessions which we archive for those who have other obligations hindering them from attending. This is to say there is no lesson missed and they are used to the concept.' 
Some of the students interviewed had this to say: "When I registered at Unisa, I did not know that I had to work independently and alone. It took me some few weeks to settle down." "Internet and cell-phones have made our lives easy because we are able to help each other with our studies" This statement indicates that the future of open and distance learning is more mobile, more connected and more personalised. Similarly, a programme manager working in one of the departments at the University of South Africa was heard giving the following comment: 'I see technology as encouraging more group participation, more sharing, less willingness to be afraid of change.'

The above provides anecdotal evidence of how a shift in learning culture is understood by instructors and education specialists who interact regularly with learners and their use of technologies. Participants in this study commented on the relationship that learners have with technology. Some say learners are comfortable with it, others that they are fascinated by it, and one e-Learning specialist aptly stated that students are fearless with technology: 'They are digital natives and hence want to participate in the creation and management of learning environments. Educators have to change to accommodate this new change'. Despite the adoption of an ICT policy by the University of South Africa there is still a need to train students on how to use ICTs. Conscious efforts are being made to train students and workers in ICT. There is general acknowledgment of the rapid advancement of technology and the necessity to be part of it. However, a more pessimistic outlook is expressed by many educators who fear that mobile technology is about to replace them as shown in the following statement: 'There has been a great misunderstanding with the training that has been used to introduce the integration of ICT in education and training: the methods used have created more fear among teachers than interest. Educators fear that ICT is meant to replace them.' We need to introduce ICT through the teacher training colleges instead: if teachers are taught how to use ICT during their normal lessons, they will adopt it more. In characterising this relationship with technology, an educational technologist based at (Unisa) stated: 'Students are of a new generation where electronic communication and electronic access to materials become a habit and a way of living. It reduces the cost of textbooks. With electronic access, they can have access anywhere, any time and that makes learning much more accessible to them.'

\section{Findings, Implications and Recommendations}

This study was only an attempt to shift educational thinking into a more student-centred approach that would allow both the student and the university to have easy access to each other by closing the psychological gap that exists between the learner and the instructor through the use of mobile technology. Even though the study did not get a clear-cut theoretical framework based on the use of mobile technology to reduce the gap between the student and the educator, it however, revealed that new technologies especially mobile technologies are now challenging the traditional concept of distance education, because they offer a very hopeful way to reach the vast population of the developing countries as it does not require band-with connections. The study found that through mobile learning, many disadvantaged people might be brought into the centre from the margins of society to participate in development processes. Furthermore, the study revealed that the educational development of people themselves, not only bridge the education gap, but it as well bridges the power relations divide, especially between rural communities of the developing economies. The study also revealed that mobile technology has the potential to reduce the distance out of distance education.

The study found that reaching the disadvantaged has been identified by several studies as one of the reasons for exploring the use of mobile or wireless devices in learning. Although the use of cell phones is ubiquitous in South Africa, using cellular technology for mobile learning does have limitations, which must both be recognised and dealt with accordingly. The study also managed to find out that every technology has some limitations and weaknesses, and mobile devices are no exception. This assertion is supported by McNeal and Van't Hooft (2006) who summarized these problems as follows: physical attributes of mobile devices, such as small size, heavy weight, inadequate memory, short battery life span, challenge in learning how to work with a mobile device, physical environment issues such as problems with using the device outdoors, excessive screen brightness, and so on. It is envisaged that mobile producers would take care of these problems in the near future (Visser \& West, 2005). Having looked at the findings and implications, the study therefore recommends that an early intervention by academics and the university structures should not be ignored if distance education students are to be supported through mobile technology. In this study the researcher recommends that for effective learning support to take place, the transactional presence of the ODL institution, staff and tutors are critically important for all distance learners, irrespective of their geographical location. The more positive the learners' perceptions and experiences of institutional support, the greater their interest and motivation, and the more likely effective learning is to occur (Holmberg, 2003, Shin, 2003).

Furthermore, the study recommends that financial and appropriate human resources should be mobilised to 
enhance learning support initiative that support the implementation of mobile technology as a learning tool. Although the study did not pay attention to all the mobile technologies that we can use to bridge the gap between the student and educator, student and peers, student and the institution, the study was able to discover the importance of using cell phone as a learning tool. Furthermore, the study argued that, whatever else it does, mobile technology must provide greater opportunities for reducing the gap or distance that previously existed between the student and the instructor. Finally, the study found that an understanding of students' concerns on how to bridge the gap between them and their educators using mobile technology would go a long way in improving their success in open and distance learning.

\section{Conclusion}

There is no doubt that the use of mobile technology in education is here to stay. Costs will come down and functionality will increase. Developments in mobile learning will be driven by the younger generation of "digital natives," but they will need support (Mishra, 2009). However it is not at all safe to assume that because someone is young they will be able to obtain the maximum benefit from mobile learning without support. Mobile technology will continue to be used in a variety of environments; for example, within the classroom, anywhere, anytime and particularly at home, on field trips for a variety of purposes; for example, for administration, learner support, whole course and perhaps, in due course for fully accredited, stand-alone courses (Mishra, 2009). But through mobile learning, even the disadvantaged people who cannot afford to give up their jobs for fulltime studies; cannot pay for fulltime studies unless working and cannot be away from family or social responsibilities, they can receive education and participate in development at the same time. Therefore, the potentials of mobile learning calls for our attention as instructional designers and educators to rethink strategies that can facilitate the use of mobile devices as support for learning as they might be the tools we have all been looking for, especially for developing economies, where fixed cyber infrastructure is very low. In conclusion the researcher argues that mobile technologies, cell phones in particular, are a perfect vehicle for making educational opportunities accessible to rural learners to places and times that are more convenient than formal schooling.

\section{Reference}

Alexander, B. (2004). Going Nomadic: Mobile Learning in Higher Education. EDUCAUSE Review, September/October 2004. 39(5), 2835. Retrieved 15th May 2013.http://www.educause.edu/pub/er/erm04/erm0451.asp.

Attewell, J. 2005. From research and development to mobile learning. Tools for education and training providers and their learners. http://www.mlearn.org.za/CD/papers/Attewell.pdf (accessed 13 May 2013).

Brown, H.T. (2003). The role of m-learning in the future of e-learning in Africa, 2003, ICDE World Conference.

Colliazi, P.F. 1978. Psychological research as the phenomenologist views it. Oxford: Oxford University Press.

Garrison, D.R \& Shale, D. (Eds.) (1990). Education at a distance: From issues to practice. Florida: Robert E. Krieger Publishing Company.

Holmberg, B. (2003). Distance Education in essence. Oldenburg: Bibliotheks-und information system der Universitat Oldenburg.

Januszewski, A \& Yeaman, A. (2001). Educational technology: The development of a concept. New York: Libraries Unlimited.

Jung, I. (2001). Building a theoretical framework of web-based instruction in the context of distance education. British Journal of Educational Technology, 32(5), 525-534

Keegan, D. (2006). The incorporation of mobile learning into main stream education and training. Paper presentation, mLearn 2005 , the $4^{\text {th }}$ world conference on mobile learning, October 25-28, Cape Town, South Africa.

Khan, B.H. (2001). Web-based training. Eaglewood Cliffs, New jersey: Educational Technology Publications

Librero, F. (2006). Trends in e-learning of interest to educators. Paper presented in the National Conference of the Philippine e-Learning Society 28-29 November 2006. Diliman, Quezon City, Philippines.

Makoe, M. (2012). Linking Mobile Learning to the Student-Centred Approach. (Retrieved 18th April 2013). http://www.checkpointelearning.com/article/8044.html.

McNeal, T \& Van't Hooft, M. (2006). Anywhere, Anytime: Using mobile Phones for Learning. Journal of the Research Centre for Educational Technology. Retrieved 29th May 2013.

Mishra, S. (2009). Mobile Technologies in Open Schools. Vancouver: Commonwealth of Learning

Moore, G.M. (1991). Distance Education Theory. The American Journal of Distance Education, 5(3), 1-6.

Moore, G.M. (2003). Handbook of Distance Education. The American Journal of Distance Education, 17, 73-75.

Shin, N. (2003). Transactional presence as a critical predictor of success in distance learning. Distance education, 24(1), 71-76

Stead, G. (2006). Mobile Technologies: Transforming the future of learning. In Emerging Technologies for Learning, British Educational Communications and Technology Agency, ICT Research, Coventry, 6-15, Retrieved 13 May 2013.

Suplido, M., Bonito, S., Escubio, M \& Mariano, L. (2003). 700UPOU: Finding educational uses for ubiquitous SMS (texting) technologies. Los Banos, Phillipines: Phillipines Open University.

Thorpe, M. (2002). Rethinking learner support of collaborative online learning. Open Learning, 17(2), 105-119 
Venter, K. (2003). Coping with isolation: The role of culture in adult distance learners' use of surrogates. Open Learning, $18(3), 1-7$.

Viljoen, J., Du Preez, C \& Cook, A. (2005). The case for using SMS Technologies to support distance education students in South Africa: Conversations. In Perspectives in Education. 23(4), 115 - 122

Visser, L \& West, P. (2005). The Promise of m-learning for Distance Education in South Africa and Other developing Nations. In Y.Visser, L.Visser, M. Simonson, \& R. Amirault (Eds.) Trends and Issues in Distance Education: International perspectives,117129. Greenwich, CT: Information Age Publishing. 